\title{
Changes in types of muscle fibers induced by transcutaneous electrical stimulation of the diaphragm of rats
}

\author{
D. Costa ${ }^{1,2}$, K.M. Cancelliero ${ }^{1}$, G.E.R. Campos ${ }^{2,3}$, T.F. Salvini ${ }^{1}$ and C.A. da Silva ${ }^{2}$ \\ ${ }^{1}$ Departamento de Fisioterapia, Universidade Federal de São Carlos, São Carlos, SP, Brasil \\ 2Departamento de Fisioterapia, Universidade Metodista de Piracicaba, Piracicaba, SP, Brasil \\ ${ }^{3}$ Departamento de Anatomia, Universidade Estadual de Campinas, Campinas, SP, Brasil \\ Correspondence to: D. Costa, Departamento de Fisioterapia, Universidade Federal de São Carlos, \\ Rodovia Washington Luís (SP-310), km 235, 13565-905 São Carlos, SP, Brasil \\ E-mail: dirceu@power.ufscar.br
}

\begin{abstract}
The objective of the present study was to assess the effect of transcutaneous electrical diaphragmatic stimulation (TEDS) on different types of diaphragm muscle fibers. Male Wistar rats (8-12 weeks old) were divided into 2 experimental groups ( $\mathrm{N}=8$ in each group): 1) control, 2) animals submitted to TEDS [frequency $=50 \mathrm{~Hz} ; \mathrm{T}_{\mathrm{ON}} / \mathrm{T}_{\mathrm{OFF}}$ (contraction/relaxation time) $=2 / 2 \mathrm{~s}$; pulse duration $=0.4 \mathrm{~ms}$, intensity $=5 \mathrm{~mA}$ with a $1 \mathrm{~mA}$ increase every $3 \mathrm{~min}$ for $20 \mathrm{~min}$ ] for 7 days. After completing this treatment period, the I, IIA, IIB, and IID diaphragm muscle fibers were identified using the mATPase technique. Statistical analysis consisted of the normality, homoscedasticity and $t$-tests $(P<0.05)$. There was a $19.6 \%(P<0.05)$ reduction in the number of type I fibers and a $49.7 \%$ increase $(P<0.05)$ in type IID fibers in the TEDS group compared with the control group. An important result of the present study was that electrical stimulation with surface electrodes was efficient in altering the distribution of fibers in diaphragm muscle. This therapeutic resource could be used in the treatment of respiratory muscle alterations.
\end{abstract}

Key words: Diaphragm; Transcutaneous electrical stimulation; Muscle fiber

Research supported by FAPESP (\#04/14798-5). K.M. Cancelliero is the recipient of a fellowship from FAPESP.

Received June 15, 2007. Accepted August 21, 2008

Pette and Vrbová (1) have reported that muscle tissue shows the characteristic of functional plasticity, that is, of adapting according to the stimulus applied. For example, neuromuscular electrical stimulation can lead to a change in the distribution of muscle fiber types. Diaphragmatic electrical stimulation has been used to improve ventilatory function (2); however, studies are necessary in animal models that permit muscle biopsy because the few that exist are directed to an invasive approach in humans with internal electrodes (3). Similar studies cannot be carried out in humans with justification due to ethical limitations. Thus, the present animal study may provide relevant information related to changes in the distribution of the types of diaphragm muscle fibers by the non-invasive application of transcutaneous electrical diaphragmatic stimulation (TEDS) using surface electrodes. Most of the reported studies are related to invasive diaphragmatic electrical stimulation in animals (4).

During rehabilitation, the diaphragm muscles in humans are usually treated with electrical stimulation applied daily or on alternate days using surface electrodes. To our knowledge, there are no previous reports evaluating the effect of electrical stimulation applied using surface electrodes in the diaphragm muscle of the rat. Thus, the purpose of the present study was to assess a possible effect of a clinical-like electrical stimulation treatment in the distribution of fiber types of diaphragm muscle of the rat. The results of this study can probably be extrapolated to patients for the treatment of diaphragm muscle using surface electrical stimulation.

Male albino Wistar rats (8-12 weeks old) had food and water ad libitum and were submitted to a 12-h light/dark 
photoperiodic cycle. The rats were divided into two experimental groups ( $N=8$ animals in each group): 1) control (C), 2) animals submitted to daily TEDS for 7 consecutive days. The Ethics Committee for Animal Experimentation of UNICAMP approved the study (\#754-2/2004).

The animals were anesthetized daily [Rompun ${ }^{\circledR}$ (12 $\mathrm{mg} / \mathrm{kg}$ xylazine)/Dopalen ${ }^{\circledR}$ (95 mg/kg ketamine), ip] before TEDS application, and the anterior chest region shaved to guarantee greater effectiveness of the stimulation and of electrode positioning. Twenty minutes of TEDS was carried out daily for 7 days, using a frequency of $50 \mathrm{~Hz}$ (cycle per second), $2 \mathrm{~s} \mathrm{~T}_{\mathrm{ON}}$ (contraction time), $2 \mathrm{~s} \mathrm{~T}_{\mathrm{OFF}}$ (relaxation time), for a total of 300 contractions per session, and a $0.4-$ ms phase width (pulse duration). The intensity (pulse amplitude) was set at $5.0 \mathrm{~mA}$ on the basis of the observed muscle contraction. An increase of $1.0 \mathrm{~mA}$ was applied to the current every $3 \mathrm{~min}$ to minimize accommodation of the diaphragm to the stimulus.

A Dualpex 961 (Quark ${ }^{\circledR}$, Brazil) equipment with two silicone-carbon $(1.5 \times 2.0 \mathrm{~cm})$ electrodes was used for electrical stimulation. The electrodes were positioned bilaterally on a layer of contact gel on the lateral region of the chest between the 4th and 6th ribs. This region is close to the lateral branches of the phrenic nerve, which enervate the diaphragmatic cupolas. It is important to mention that our previous study did not observe any alteration in the cardiac system upon stimulation (5).

After stimulation, the animals were beheaded and the diaphragm removed immediately. The muscle fragment collected (left hemi-diaphragm, costal part) was positioned on a wooden block using tragacanth gum and frozen in isopentane cooled in liquid nitrogen at $-159^{\circ} \mathrm{C}$, subsequently being stored in a bio-freezer at $-74^{\circ} \mathrm{C}$ for posterior microtomy. Microtomy of the muscle fragment in a mi-

Table 1. Number of type I, IIA, IIB, and IID fibers of diaphragm muscles identified by the mATPase method after transcutaneous electrical diaphragmatic stimulation (TEDS) of the rat.

\begin{tabular}{lcc}
\hline Fiber type & Control & TEDS \\
\hline I & $181.7 \pm 30.7$ & $146.1 \pm 21.4^{*}$ \\
IIA & $100.3 \pm 27.4$ & $108.2 \pm 29.2$ \\
IIB & $49.1 \pm 25.2$ & $37.2 \pm 13.5$ \\
IID & $54.3 \pm 20.6$ & $81.3 \pm 19.4^{*}$ \\
\hline
\end{tabular}

Data are reported as means $\pm \mathrm{SD}$ for $\mathrm{N}=8$ in each group. A total of 1500 fibers were observed for each rat.

${ }^{*} \mathrm{P}<0.05$ compared to the control group (Kolmogorov-Smirnov, Student $t$-test). crometer, Microm HM 505E cryostat (Microm, Germany), was used to obtain $12-\mu \mathrm{m}$ sections at $-24^{\circ} \mathrm{C}$, which were stored at $-74^{\circ} \mathrm{C}$. All sections were simultaneously submitted to histochemical evaluation. The main types of fiber were delineated using the mATPase technique according to Staron (6), after pre-incubation at $\mathrm{pH} \mathrm{4.3,} 4.55$ and 10.5 (7). Using a trinocular microscope (Olympus, Japan) plus the Camedia Master program, photo mounts of all sections at the different $\mathrm{pH}$ values were made, allowing for the determination of the number and percentage of each type of fiber, including I, IIA, IIB, and IID. Three areas were selected in each muscle specimen and a total of 1500 fibers were classified for each animal.

Statistical analysis was carried out using the Kolmogorov-Smirnov normality test and the homoscedasticity test (Bartlett's criteria). Since the variables showed normal distribution and homoscedasticity, the Student $t$-test was used to compare groups. A critical level of $5 \%(P<0.05)$ was used for all calculations and the software used was GraphPad Prism 3.02 ${ }^{\circledR}$.

The group that received TEDS daily for 7 days showed a significant decrease of $19.6 \%(P<0.05)$ in the number of type I fibers and a $49.7 \%$ increase $(P<0.05)$ in the number of type IID fibers compared with the control group. There was no significant difference $(P>0.05)$ between groups for the percentages of type IIA and IIB fibers (Table 1).

The rat diaphragm is composed of a mixture of fiber types, although denervation, ageing and corticosteroid treatment may lead to significant atrophy of types IIX and IIB fibers, in addition to altering the distribution of muscle fiber types and decreasing muscle strength (8-11). Chronic obstructive pulmonary disease is characterized by the transformation of type II muscle fiber into type I and this process may contribute to a decrease in diaphragm muscle strength (12).

We have shown here that TEDS, applied at $50 \mathrm{~Hz}$ for a short period of time with surface electrodes, led to alterations in the distribution of fibers, with a decrease in type I and increase in type IID fibers. This increase could be explained by the frequency of the current used. This result could be beneficial in patients with respiratory muscle dysfunction, since it alters the type of muscle fiber, amplifying the proportion of fast-contracting muscle fibers, which are normally decreased in these diseases and are also associated with ageing.

Although future studies in humans with this type of protocol should be carried out, the results presented here indicate that electrical stimulation of the diaphragm may be a selective and efficient resource to alter muscle fiber type. 


\section{References}

1. Pette $D$, Vrbova G. What does chronic electrical stimulation teach us about muscle plasticity? Muscle Nerve 1999; 22: 666-677.

2. Cuello AF, Masciantonio L, Mendoza SM. Estimulation diafragmatica eletrica transcutanea. Med Inten 1991; 8: 194-202.

3. Ayas NT, McCool FD, Gore R, Lieberman SL, Brown R. Prevention of human diaphragm atrophy with short periods of electrical stimulation. Am J Respir Crit Care Med 1999; 159: 2018-2020.

4. Geddes LA, Voorhees WD, Bourland JD, Riscili CE. Optimum stimulus frequency for contracting the inspiratory muscles with chest-surface electrodes to produce artificial respiration. Ann Biomed Eng 1990; 18: 103-108.

5. Cancelliero KM, Silva CA, Costa D. Transcutaneous electrical stimulation of the diaphragm improves the metabolic conditions of respiratory muscles in rats. Braz $J$ Phys Ther 2006; 10: 59-65.

6. Staron RS. Human skeletal muscle fiber types: delineation, development, and distribution. Can J Appl Physiol 1997; 22: 307-327.
7. Guth L, Samaha FJ. Procedure for the histochemical demonstration of actomyosin ATPase. Exp Neurol 1970; 28: 365-367.

8. Aravamudan B, Mantilla CB, Zhan WZ, Sieck GC. Denervation effects on myonuclear domain size of rat diaphragm fibers. J Appl Physiol 2006; 100: 1617-1622.

9. Prakash YS, Miyata H, Zhan WZ, Sieck GC. Inactivityinduced remodeling of neuromuscular junctions in rat diaphragmatic muscle. Muscle Nerve 1999; 22: 307-319.

10. Verheul AJ, Mantilla CB, Zhan WZ, Bernal M, Dekhuijzen PN, Sieck GC. Influence of corticosteroids on myonuclear domain size in the rat diaphragm muscle. J Appl Physiol 2004; 97: 1715-1722.

11. Yang L, Bourdon J, Gottfried SB, Zin WA, Petrof BJ. Regulation of myosin heavy chain gene expression after shortterm diaphragm inactivation. Am J Physiol 1998; 274: L980L989.

12. Levine S, Gregory C, Nguyen T, Shrager J, Kaiser L, Rubinstein $\mathrm{N}$, et al. Bioenergetic adaptation of individual human diaphragmatic myofibers to severe COPD. J Appl Physiol 2002; 92: 1205-1213. 